\title{
Eu e o outro: a Unesco e a educação comparada
}

\author{
Candido Alberto Gomes
}

\section{Resumo:}

A educação comparada se defronta com o desafio da relação eu-outro, por buscar conhecer outras realidades. A relação tornou-se mais urgente à medida que o mundo se torna interdependente. Após a Grande Guerra o multilateralismo se fortaleceu com a Liga das Nações e organizações educacionais. Ainda durante a Segunda Guerra Mundial, os governos britânico e no exílio hauriram das experiências anteriores princípios para fundar a Unesco, tendo como núcleo o direito humano à educação. Tomando o caminho da atuação global, inclusive no campo do desenvolvimento, a Organização contribuiu grandemente para tecer redes globais e estimular a educação comparada e internacional, por meio sobretudo do Bureau Internacional de Educação. Nesta trajetória, a disciplina enfrenta novos problemas e tendências teóricas e metodológicas, como o quantitativismo e a pressão da competitividade interpaíses. Em meio às contradições e incertezas, a Unesco, há mais de 70 anos, vem situando a diversidade na centralidade dos desafios e organizando espaços para o diálogo entre os diferentes.

Palavras-chave:

Educação comparada e internacional; Unesco; globalização; desenvolvimento; migrações. 


\title{
Me and the other: Unesco and comparative education
}

\begin{abstract}
Comparative education faces the challenge of the relation between the other and me, since one of their purposes is to know other realities. The difficulty of such a relation has increased because of the world interdependency. After the I WW, multilateralism became stronger with the League of Nations and new educational organizations. During the II WW the British government and those in exile looked for previous experiences in order to build Unesco on the basis of the human right to education. As the new Organization opted for world scale activities, as well as those of development, it contributed significantly to construct global networks, so stimulating comparative and international education, in particular by the International Bureau of Education. In its developments, this discipline has had new theories and methodological approaches, as the statistical exacerbation and pressures for international competition. However, despite contradictions and uncertainties, Unesco has included diversities as central challenges for over 70 years, has organized spaces for dialogue among those different and has contributed to the reduction of discrimination.
\end{abstract}

Key words: Comparative and international education; Unesco; globalization; development; migrations.

\section{El otro y yo: Unesco y la educación comparada}

Resumen: La Educación Comparada tiene el desafío de las relaciones entre los otros y yo. Tales relaciones se tornaron más urgentes en la proporción que el mundo se hizo más interdependiente. Después de la Primera Guerra Mundial el multilateralismo se fortaleció con la Liga de las Naciones y organizaciones educativas. Durante la Segunda Guerra, los gobiernos británicos y en el exilio revisaron experiencias anteriores, con vistas a la fundación de la Unesco, basándose en el derecho humano a la educación. La Organización siguió el camino de la actuación global, incluso del desarrollo. Así, construyó redes globales, para lo que tuvo que estimular la Educación Comparada e Internacional. En su trayectoria, esta disciplina enfrenta continuamente nuevos desafíos teóricos y metodológicos, como la exacerbación estadística y las presiones por la competición internacional. Sin embargo, a pesar de las contradicciones e incertidumbres, Unesco sigue incluyendo las diversidades como desafíos centrales por más de 70 años. También sigue en la organización de espacios para el diálogo entre los diversos y en la reducción de la discriminación.

Palabras clave: Educación comparada e internacional; Unesco; globalización; desarrollo; migraciones.

\section{Moi et les autres: I'Unesco et l'Éducation comparée}

Résumé: L'Éducation comparée affronte le défi des relations entre moi et les autres, comme une conséquence de son ouverture à d'autres réalités. Ce difficile rapport acquiert une urgence croissante avec l'interdépendance du monde. Après la Grande Guerre, le multilatéralisme a gagné de l'intensité avec la Société des Nations et les organisations éducatives. Pendant la Seconde Guerre Mondiale, le gouvernement britannique et des gouvernements en exil ont analysé les expériences antérieures afin de fonder l'Unesco. Cette nouvelle organisation s'est appuyée sur le droit humain à l'éducation. En empruntant la voie de l'action mondiale, y compris dans le domaine du développement, cette organisation a grandement contribué à tisser des réseaux mondiaux et à stimuler la comparaison et l'éducation internationale, en particulier par le Bureau International de l'Éducation. Dans cette trajectoire, cette discipline est confrontée à de nouveaux problèmes et à des tendances théoriques et méthodologiques, telles que le quantitativisme et la pression de la compétitivité internationale. Au milieu des contradictions et des incertitudes, l'Unesco a depuis plus de 70 ans situé la diversité comme un défi central, organisant des espaces pour le dialogue parmi les différences et la réduction des discriminations.

Mots-clés: Éducation comparée et internationale; Unesco; mondialisation; développement; migrations. 
No princípio era a diferença. A diferença ergueu barreiras de estereótipos e preconceitos entre nós e os outros. Um fenício, para Homero (1997), era uma caricatura do real, predominando o olhar daquele que via em face do sujeito visto. Os gregos, etnocêntricos, situavam-se no umbigo do mundo, o santuário de Apolo, em Delfos. Os outros eram bárbaros, como os germânicos de Tácito (1999), em oposição aos romanos, superiores a todos. Em decorrência, para o nosso grupo se reserva(va) a lealdade; para os outros, a legitimação do poder e da violência, já que não tinham (têm) a plenitude da condição humana. E assim se hierarquizaram as diferenças entre superior/inferior, normal/anormal, opresssor/oprimido e o oprimido que pode se tornar opressor. No seio das contradições, as ilhas constituintes da ecúmene, espaço habitado pelo homem, aproximaram-se mais pela dominação que pela troca simétrica. No fascínio pelo outro, ilhas se tornaram arquipélagos, enquanto os arquipélagos reunidos fizeram surgir a terra inteira, "redonda, do azul profundo" (Pessoa, 2014). Não bastando, fios, cabos e ondas aproximaram ainda mais o globo, em interdependência crescente, em que todos singram na mesma terra redonda, configurando as metáforas sociológicas da sociedade em rede (Castells, 2011) e da sociedade de risco (Beck, 2013).

Conforme o rastreamento histórico, os racismos se formaram por projetos de dominação e criação de minorias em termos de poder político, mas não só pelos europeus. A Europa, desde a expansão martítima, tem sido uma área estratégica, mas não a única, para a estratificação de "raças". Suas relações de superioridade em face dos demais continentes incidem nas alegorias da gravura de Ortelius, Theatrum Orbis Terrarum (Bethencourt, 2015). Entre elas a surpresa, o continente novo da América, não inserido antes na ecúmene, mas cada uma com a sua fisionomia derivada da participação mais ou menos subalterna na divisão internacional do trabalho. A Europa, com coroa, cetro e cruz, aparece à frente, sentada. Abaixo e à direita, de pé, vem a Ásia, ricamente vestida, e à esquerda a África, representada por uma mulher quase nua. Deitada ao fundo, mais nua que a África, traduzindo um suposto vazio cultural, vem a América, tendo à mão esquerda a cabeça decepada de uma vítima de canibalismo.

Desde a pré-História, como pano de fundo, povos nômades e relativamente sedentários deslocam-se em busca de maiores recursos, tornando-se, assim, "invasores". Cada onda de movimentos humanos incendeia o pânico em face da sucessão de estranhos que batem à nossa porta (Bauman, 2017). Quando os hospedeiros os vencem, a eles são alocados os piores nichos no espaço social. A situação no século XXI se agrava não porque os "invasores" venham armados para ocupar terras ou praticar a rapina, como os germânicos, vikings, mongóis, hunos e outros "bárbaros". Ao contrário, eles vêm na sua fragilidade, em grande número, e parte considerável perece em naufrágios, antes de atingirem um ponto de chegada. Já que nada têm, buscam um lugar onde possam ter e ser alguma coisa, como eventuais titulares de direitos humanos. 
Os migrantes são emigrantes sem lugar que não chegam a ser imigrantes. Em busca do exílio, desprovido do halo romântico do século XIX, antes que cheguem a algum lugar já são estigmatizados como suspeitos, ameaçadores e perigosos (Nouss, s/d.). Seu delito é a própria existência no espaço social e legal. Uma parte deles, na categoria de "refugiados", passa de vítimas a culpados e, se não devolvidos às origens, permanecem em não lugares (Augé, 2010). Estes são instalações necessárias à circulação acelerada de pesssoas e bens por oposição à noção sociológica de lugar. Augé destaca o paradoxo de existir hoje uma unidade pensável do espaço terrestre enquanto emergem particularismos e individualização. Apesar do elevado fluxo de pessoas, porém, o estrangeiro sociológico não passa despercebido, ele que ata as duas pontas de um fio, o próximo ao longínquo, na relação entre o distanciamento do próximo e a proximidade do longínquo (Simmel, 2012). Por isso, o estrangeiro, ao mesmo tempo que desafia a curiosidade, é estranho tratado com estranheza. Quando em grande escala, assombra e amedronta, de modo a ser expulso ou proibido de entrar em lugares. Camus (2008) o situa como uma pessoa estranha, que age contra as expectativas e acaba condenado pelo absurdo do mundo.

Por isso mesmo, aos refugiados se reservam os campos, na verdade, prisões onde perduram até várias gerações, em regime de vita minima, verdadeiras máquinas de moer gente, com baixos indicadores de educação e saúde, além da erosão da subjetividade humana, Estes não lugares sugam a dignidade e proscrevem os direitos humanos. São heterotopias para Foucault (2004), pelo que os corpos moídos estão em outros lugares do mundo que não o mundo, verdadeiros campos ou esconderijos, como o Anexo de Anne Frank. No caso dos Frank e tantos outros, constituía uma boIha frágil, capaz de se desfazer subitamente, com a visita da polícia nazista para conduzi-los aos campos de concentração. Por sua vez, estes são os piores não lugares, onde se amontoam pessoas à espera da morte quase certa, pois o poder decidiu que as minorias não merecem viver.

Que nos diz a educação comparada e internacional sobre estas pessoas e seus não lugares? De fato, existe significativa literatura, incluindo relatos de pesquisas e ações diante dos duros problemas do nosso tempo, patenteando que comparatistas não se omitem. Todavia, trabalhos podem não estar isentos de vieses, pelo mesmo medo do estrangeiro, que muito provavelmente será relegado, quando relegado, às camadas mais baixas da estratificação social, como acontecia aos "cristãos novos" ou aos moçárabes da Península Ibérica. Lá a Santa Inquisição, sob a capa do sagrado, foi reguladora da estratificação social (Bethencourt, 2015), como também ator político, a exemplo dos nauseantes processos de Joana d'Arc (Duby \& Duby, 1973). Da mesma forma que os judeus em numerosos guetos medievais, os estrangeiros permanecem discriminados, em péssimas condições de vida, de modo que não se constituam uma ameaça, em estado de não direito. 
Ontem como hoje as barreiras se erguem e as portas se fecham. Apesar da modernidade, do lluminismo e da llustração, a essência comum da dignidade e dos direitos humanos não leva a palma sobre as teias de diversidades.

As diferenças se caracterizam como vetores de poder, a definir minorias e maiorias, chegando aos genocídios do século XX. Desta relação entre o Eu e o Outro brotam movimentos de lealdade e deslealdade mútuos, como se coexistissem dentro de cada um de nós Abel e Caim, Eros e Tânatos.

Com efeito, a educação comparada está no foco destes cruzamentos. Campo inter/multi disciplinar, com várias dimensões comparativas, à medida que mergulhamos no seu âmbito (Amaral, 2015), sua conjugação de luzes e sombras requer os cuidados com o afastamento relativo em face dos objetos e envoltórios ideológicos, capazes de usá-la desde um meio de compreensão até o veneno da superioridade e dos tipos únicos, nada diferente da hierarquia continental de Ortelius.

\section{Educação comparada e internacional}

Filha da globalização do século XIX, esta disciplina começou como fruto da cooperação entre sistemas nacionais de educação. Significativamente, o comparatista era um estrangeiro em busca de estrangeiros sociológicos. Não era nômade, mas o estrangeiro sociológico em busca de novas experiências. Os ventos das mudanças impulsionavam-nos à busca de alternativas para a educação. Em vez de os educadores permanecerem em suas ilhas nacionais, era preciso discutir, buscar e encontrar experiências, em certos casos com o intuito copiativo de identificar o "melhor", em outros como luzes para adequar aos contextos necessariamente diversos. Daí o congraçamento de comparatistas em Genebra e outros sítios, à procura da renovação e atualização. A Educação Nova inspirava a busca do tempo perdido em Portugal, em sua relativa periferia da Europa. O mesmo ocorria no Brasil e outros países latino-americanos, na sua incipiência e autoritarismo pedagógicos. O jorro da renovação, de fora para dentro, levou a uma série de mudanças, apesar dos obstáculos do poder, em duros tempos de fascismo, entre as duas Guerras Mundiais (Jesus \& Gomes, 2016). Filosoficamente bem estruturada, a Educação Nova permeou, nos Estados Unidos, mais a administração que os currículos. De fato, a escola para a democracia, o aluno como sujeito e os métodos ativos suscitavam desconfiança de que os adultos "perdessem o controle", conquanto hoje a crise escolar leve cada vez mais à sensação de perda e concessão, na busca de ceder os anéis para salvar os dedos. Sua função custodial da juventude ainda se mantém, apesar dos limites cada vez maiores como elevador social. 


\section{Atração e fuga do centro}

Entre o denominador comum da dignidade humana e do direito à educação, por um lado, e as diferenças culturais e políticas, por outro, manifestam-se duas tendências contraditórias, de diferenciar e de unir. Por um lado, afetamo-nos uns aos outros por estarmos cada vez mais perto, ou seja, há um magnetismo coesivo. Um movimento num lugar afeta outros, em condições similares, como Maio de 1968 ou a Primavera Árabe, (2010). Por outro lado, as divisões se erguem e acumulam, inclusive no regionalismo, gerando um mundo multipolar e diversificado. Numa visão rápida de marcos miliários, cabe assinalar a Paz de Westfália, em 1648, que encerrou as guerras de religião e resultou da primeira reunião diplomática em nível europeu, diga-se mundial, já que o mundo era eurocêntrico. Não tendo garantido uma paz duradoura e considerando as guerras imorais, Kant (2008) elaborou o seu projeto de paz perpétua, que antecipou uma organização multilateral como a Liga das Nações ou as Nações Unidas.

O princípio de equilíbrio, estatuído em Westfália, foi violado logo no início do século XX, com a Grande Guerra. O aumento da interdependência envolveu número maior de países, alinhados em blocos, envolvendo todos os continentes. Ingênua ou maliciosamente dita como uma guerra para encerrar todas as guerras, levou o mundo a se tornar uma usina de alta pressão, conducente a uma segunda guerra, de proporções ainda mais amplas. É bem verdade que organizações multilaterais vicejaram a partir do fim da Primeira Guerra Mundial, como a Cruz Vermelha e o Crescente Vermelho (1919), além da própria Liga das Nações. O sonho da paz e do entendimento permaneceu vivo durante alguns anos, apesar dos graves problemas da Paz de Versalhes, pouco duradoura por carecer do senso de justiça e realidade. Entretanto, continuou a faltar uma instância supranacional, em plena era dos nacionalismos exacerbados, para estabelecer a paz com eficácia. Por isso, o entendimento cedeu à contemporização com o Eixo, num perigoso processo de "ganhar" tempo.

\section{Antecedentes}

A atração de educadores e intelectuais por âmbitos internacionais de debate já se fazia sentir há tempos, inclusive por meio da educação comparada, quando terminou a Primeira Guerra Mundial. Pontos de encontro desvelavam similaridades e diferenças não mais recônditas nos sistemas nacionais de educação, mas como pré-participantes de uma cidadania global. Assim, as potências vitoriosas criaram a Liga das Nações, depois de Versalhes, em 1920. Preocupada com o desarmamento militar, a Liga também objetivava os aspectos morais, relacionados ao intercâmbio intelectual e à educação. Já em 1914 se havia proposto o Instituto Internacional de Cooperação Intelectual, mas este só foi estabelecido em Genebra em 1925. Da mesma forma que a educação 
comparada emergiu da constituição de sistemas educacionais nacionais, o novo órgão temia que os países sentissem uma interferência em sua soberania. Não eram receios vãos, já que o nacionalismo se amalgamou ao racismo, com alto potencial explosivo. Por isso, a cooperação internacional era uma espécie de missão ancilar da manutenção da paz, embora o cenário envolvesse ondas de refugiados, epidemias e outras dificuldades. Em face desta lacuna, criou-se o International Bureau of Education, em Genebra (2017), organização muito respeitada que se tornou, depois, intergovernamental. Ao ser fundada, era uma organização não governamental privada, iniciativa de grandes intelectuais genebrinos. Em 1929 abriu-se a qualidade de membros a países, tornando-se a primeira organização integovernamental em educação. Mantendo a sua autonomia, tornou-se parte da Unesco, atuando sobretudo na área dos currículos e da educação comparada e internacional. Publica desde 1970 a revista Prospects em várias línguas, veículo acadêmico para disseminação de trabalhos comparados e internacionais (Elvin, 1972, Pompei et al., 1972, Pedersen, 2007).

Entrando a Segunda Guerra Mundial, o pensamento não se fixou apenas nos aspectos militares e econômicos do conflito. Mesmo sob o peso de bombardeios ao Reino Unido e do ataque japonês aos Estados Unidos, em 1942, M.R.A. Butler, presidente do Conselho de Educação da Inglaterra e Gales, convidou colegas dos governos aliados no exílio para delinear, no pós-guerra, a criação de uma organização permanente de cooperação educacional. As reuniões se institucionalizaram com a presença crescente de países, formando as sementes da Unesco. Com efeito, os acontecimentos se inseriam numa trajetória significativa, rumo a uma organização multilateral das Nações Unidas para a educação. Por proposição da Conferência de Ministros Aliados da Educação, reuniu-se em Londres, de 1 a 16 de novembro de 1945, a sétima conferência plenária das Nações Unidas, com representantes de 37 países, para estabelecer uma organização educacional, científica e cultural. A presidente foi Ellen Wilkinson, ministra britânica da Educação. A Constituição entrou em vigor em 1946, em seguida à ratificação por 20 países: África do Sul, Arábia Saudita, Austrália, Brasil, Canadá, China, Dinamarca, Egito, Estados Unidos, França, Grécia, Índia, Líbano, México, Noruega, Nova Zelândia, Reino Unido, República Dominicana, Turquia e Tcheco-Eslováquia. Lembremo-nos de que a Conferência das Nações Unidas se reuniu em San Francisco e a Organização das Nações Unidas (ONU) foi constituída em 24 de outubro de 1945. Ao adotar o princípio da construção da paz na mente das pessoas, tônica da sua carta constitucional, a Unesco abraçou uma tradição idealista, de independência relativa das ideias, originada no início do lluminismo. Assim, sucedeu aos marcos da Liga das Nações e da Comissão de Cooperação Intelectual no período entre guerras.

Ainda em 1946, Anísio Teixeira, proscrito como comunista no Brasil, foi convidado a ser conselheiro de educação superior da Unesco. A ditadura havia "terminado" quando Julian Huxley, secretário geral da Organização, procurou o governo para contactar 
o Pioneiro da Educação Nova. A máquina oficial agiu com antológica mesquinhez, na rotina de afastar os competentes e incensar os medíocres: declarou desconhecê-lo e indicou outros dois nomes (Viana Filho, 2008). Huxley acabou por encontrar Anísio em Nova lorque, deixando-Ihe um convite do próprio punho. O reformador voltava à educação. Cheio de sonhos, Anísio logo viu a Unesco limitada pelo travão preferido de políticos e seus tecnocratas: o seu orçamento era menor que o da pesquisa atômica na Suíça. E deixou esta frase lapidar: "A Unesco é, ao mesmo tempo, uma obra tardia e uma obra prematura. É esta a sua contradição essencial” (Viana Filho, 2008, p. 113).

\section{Cultivando a paz na mente humana}

Em meio a cenários sociais graves e desesperadores, também com "estranhos à nossa porta", a Unesco, apesar das dificuldades, passou a desenvolver suas ações em escala mundial, tecendo novas redes e aproveitando antigas. Em vez de optar pela cooperação entre minorias de renomados intelectuais, abriu as possibilidades para uma ampla cooperação. Assim, o papel internacional da Unesco tem envolvido publicações, bolsistas, equipes de peritos, conferências internacionais, projetos internacionais de pesquisa, defesa e afirmação dos direitos humanos e muitas outras ações (Elvin, 1972). A escala adotada tem sido civilizacional e cultural, isto é, de substratos comuns a grupos de culturas a estas individualmente. As diferenças são irrefutáveis, mas o seu reconhecimento e mútua valorização se tornam imprescindíveis para a aprendizagem da convivência. A participação dos países-membros cresceu em todas as latitudes, de modo a tornar-se uma Organização ecumênica, ou seja, inclusiva em face dos espaços povoados. Um exemplo foi o ingresso da União Soviética em 1954, a reforçar a situação da Unesco no mundo bipolar da guerra fria como agente de paz.

Mais ainda, a abrangência da entidade se ampliou com a opção pelo desenvolvimento, o que constituiu relevante ponto de viragem. No mundo dividido da paz armada Leste-Oeste havia e há outros muros, como o Norte-Sul, divisor de países em desenvolvimento e desenvolvidos. Com isso, a Unesco voltou suas ações para assegurar a universalidade do direito humano à educação, apesar das desigualdades dos países e das lutas da descolonização. Para isso, a educação comparada e internacional se mobilizou para a compreensão de problemas e suas soluções. Os seus conhecimentos muito se enriqueceram ao brotarem das ações, com seus acertos e inevitáveis enganos. Esta tônica no acesso aos direitos humanos num mundo tão desigual constituiu um grandioso desafio, fértil em experiências. Em vez de se hierarquizarem diferenças verticalmente, a doutrina dos direitos humanos estabeleceu um denominador comum, ou seja, a dignidade de todos os seres humanos, em dimensão horizontal. Nesse sentido, o quadro dos 30 anos gloriosos, de alto crescimento econômico, foi altamente favorável à ajuda ao desenvolvimento, inclusive no processo de descolonização, que 
gerou numerosos países emergentes, não raro em conflitos políticos e interétnicos antes obscurecidos e agravados pela colonização. Em termos de profundidade e extensão, não há como comparar a modesta estrutura após a Primeira Guerra Mundial com a instituição existente hoje, dotada, inclusive, de numerosas parcerias governamentais e não governamentais. Ciências e tecnologias se desenvolvem para a aplicação de soluções a questões concretas, num mundo que continua desigual.

Hoje, indispensável citar, a Unesco tem agido também nas emergências resultantes de guerras e catástrofes para assegurar o direito à educação em situações particularmente difíceis. A matrícula estimada de crianças e adolescentes em programas escolares do Alto Comissariado das Nações Unidas para Refugiados, excetuando o Norte da África, em 1997/98, foi de 648 mil (Unesco, 2018). Porém, seus recursos são modestos porque a sua agenda avançada, de natureza inclusiva de países e populações, contraria poderosos interesses. Entre estes se encontra o medo pânico em face das pessoas e grupos vindos de fora, não raro vistos como criminosos reais ou potenciais, supostamente capazes de ameaçar modos de vida estabelecidos. Como a alocação de recursos se estabelece em arenas de poder, não é surpreendente que modestas verbas sejam destinadas a esta "perigosa não-gente", que, não raro, foge de conflitos não propriamente seus, mas de teatros geopolíticos de musculação das grandes potências, em busca de mais alto status, riqueza e poder.

\section{A educação comparada}

A educação comparada e internacional, como campo científico interdisciplinar, é uma das áreas de excelência, incentivada e aplicada pela Unesco. A rede de comparatistas, de perfil acadêmico, recebe a contribuição e o estímulo da Organização, que também promove a ação prática e conjugada de grupos de especialistas, quer em consultoria, quer como membros de equipes relativamente permanentes. Originada na consolidação dos sistemas educacionais nacionais, este campo científico se situa a meio caminho entre a pesquisa científica e as ações reformadoras. Com a consolidação destes sistemas nacionais a partir de 1945, ele ganhou novos interesses com a reestruturação do espaço internacional e a globalização. Mais recentemente merguIhou nos estudos quantitativos, nas classificações internacionais, na modificação de experiências e na tentativa de identificar experiências nacionais que serviriam como modelos ou exemplos a seguir (Nóvoa, 2017).

A nova senda, que inclui amplos e úteis conjuntos de dados, apresenta sérias dificuldades. Constitui grande desafio o benfazejo avanço de técnicas estatísticas, embora seja preciso reconhecer o que elas revelam e o que ocultam. Os primeiros comparatistas eram de fato mais cautelosos quanto à interdependência internacional e às dificuldades de transferência de "lições" de um lugar para outro, considerando os respectivos 
contextos histórico-culturais, que geram as diferenças. Com efeito, embora as comparações permitam novas dimensões, a cautela dos pais históricos da educação comparada inspira saudade e respeito. Compreende-se a educação num contexto envolvente, onde cada parte faz sentido no espaço geográfico e no tempo histórico comuns ou singulares (Gomes, 2015). Lembra-se a explicação da fenomenologia segundo Ortega y Gasset (2016) na cena do doente moribundo, cada personagem capta um ângulo e uma percepção. O jornalista registra os acontecimentos para seus leitores, o pintor retrata a cena para celebrizá-la, enquanto a quase viúva sofre pela iminência da morte.

Como a melhor ciência continua ainda a ser feita não industrialmente, em fábricas performáticas de conhecimento e diplomas em profusão, cumpre considerar os diversos pontos de vista, as relações entre quantidades e qualidades, as relações entre os planos global e local, a sucessão dos tempos e as caminhadas peculiares. Não basta erguer um "produto" com o seu rótulo: formar os professores como na Finlândia, embora não seja em todas as situações que se revelam os pressupostos da realidade finlandesa. É preciso perscrutar bem as raízes para algum dia conquistar asas capazes de voar, ao contrário das de Ícaro. Apesar de a educação comparada e internacional se ter originado no século XIX, novas gerações envolvem alguns "adolescentes" entusiasmados, que, diante do "novo", criam "produtos" como soluções vendáveis por altos preços, frequentemente a oferecer gatos por lebres. O mais difícil é identificar a ideologia, no sentido marxista, que dá sentido às crenças e produtos. Cumpre formular a dolorosa pergunta das investigações romanas: cui bono?, ou seja, a quem o crime beneficia? Formulada a indagação, arrancam-se os véus de uma visão deturpada, que dissimula os verdadeiros objetivos.

Entre o legado da modernidade e a nova ordem global, comparatistas e outros recebem pressões para alcançar indicadores para sobrevida na competição educacional internacional. Nesse sentido, a educação é concebida em termos de um sistema de entrega de produtos predefinidos, garantidos supostamente por processos de avaliação da qualidade (Broadfoot, 2000). Como no sonho napoleônico ou hitlerista de constituir um só império, estabelece-se um modelo de educação ocidental, a ser aplicado ao mundo todo, independente das diferenças e tensões. Veja-se que peças, como parafusos, podem ser mudados de lugar indiscriminadamente, pois supostamente transcendem as realidades contextuais. Volta-se ao fordismo, com o parcelamento das tarefas, enquanto se vive da mística de elevar os indicadores, quando todos têm limitações. Se tudo fosse simples, seria sedutor. Porém, o desafio está na aplicação dos "produtos" a diferentes latitudes, na complexidade, na falsa crença de que as mudanças levam ao contínuo "progresso", em escala evolucionista. Quanto maior a competição entre os seres vivos, maior seria o seu "aperfeiçoamento", com a seleção dos "melhores" e o desaparecimento dos "piores". Voltamos ao século XIX, século eugênico, quando as teorias raciais e os racismos vicejaram até à miséria genocida dos seguintes cem anos. 
Enquanto isso, o modelo de educação ocidental se ergue como típico da globalização, melhor que todos. Entretanto, o modelo dá marcas de entrada de água, como nas embarcações dos emigrantes. Se este modelo é tão bom, não deveria gerar uma satisfação consensual? Empregadores, políticos, comunidades, professores e alunos estariam felizes com o nível atingido de competição, de luta, de suposta excelência. Em contraste, órgãos internacionais tratam da crise da aprendizagem (não se aprenderia o quanto se deveria aprender). Sociólogos como Dubet (2002) analisam o declínio da instituição criada pela modernidade. Alunos deixam a escola por um cortejo de inconveniências, o que gera altos lucros a fornecedores de materiais educacionais para uso doméstico, além de outros. Em determinados países a profissão docente se torna perigosa, ao ponto de os profissionais abandonarem as salas de aula. A Unesco prevê falta massiva de professores (Unesco, 2017). A profissão é relegada aos menos capazes na educação superior. Muitos docentes têm problemas de saúde, pela máquina industrial em que são obrigados a entrar, e pelo tédio e violência dos alunos. Sobre isto rios de tinta têm sido usados em copiosa literatura internacional, inclusive comparada. Afinal, que vitória seria esta do modelo do Ocidente? Que vitória tem a escolarização ocidental quando se erodem a olhos vistos as conexões entre qualificações educacionais, trabalho e afluência futura? Mais adequado é tratar de uma vitória de Pirro, aquela em que o vencedor sai tão ou mais estropiado do que o vencido. Afinal, cui bono? A quem interessa todo este aparato conceitual, institucional e empresarial?

De fato, a educação comparada e internacional, marcada pela complexidade e interdisciplinaridade, pode ser fácil de "produzir", porém é extremamente difícil de elaborar e aplicar. Estas questões, que não são de hoje, merecem estudos e respostas. É preciso crítica e autocrítica, pois são inúmeros os erros acumulados, como a formação de técnicos agrícolas em Gana (King, Martin, 2002), quando os jovens e suas famílias queriam investir na educação para obter ocupações não manuais urbanas. Vimos escolas para o trabalho, em que o trabalho era o menos importante, pois importava a qualidade do currículo de educação geral. Vimos centros ocupacionais, manadas de elefantes brancos, a que quase sempre faltavam verbas de manutenção e atualização. Vimos métodos de alfabetização excelentes em si, mas que se complicavam com o bilinguismo. Encontramos belos edifícios, com projetos importados e materiais inadequados ao meio. Vimos tantas reformas reformadas abandonadas ou "digeridas" pela escola e comunidade, simplesmente porque ninguém Ihes explicou o sentido e a utilidade. Vimos avaliações de larga escala em países onde as escolas não têm sequer (até hoje) quadro de giz ou outro material, apenas a voz de professores leigos. E os avaliadores contratados esmiuçavam explicações minuciosas para o insucesso escolar. Cansamos de ver tentativas de democratização pervertidas pela falta de consciência, anuladas pelo paternalismo/filhotismo. Sofremos quando saíamos do Poder Legislativo para a realidade in loco da aplicação das leis, atravessadas por numerosos filtros de Brasília à escola. Aprendemos a tratar 
cuidadosamente os Diários Oficiais e a identificar as ricas imaginações que desviam a lei, pois duas tarefas eram fazer a lei e prever seus riscos de distorção. Aprendemos dolorosamente com a precariedade e a negligência, sob o pretexto da "falta de recursos", fazem de boas leis sombras fugidias, prejudicando quase sempre os mais pobres, numa sociedade assimétrica cuja arquitetura existe para mantê-la assimétrica. Aprendemos com dirigentes de educação, inclusive ministros africanos de cabelos brancos, o quanto as soluções simples são relevantes, sem desprezar a complexidade. Também aprendemos sobre a repetência com a fala de crianças de sete anos, numa escola rural entre auracárias, mais expressivas que os grandes teóricos. Sentimos inúmeras vezes as tensas contradições entre secretarias e escolas, cada qual com saberes limitados, para não falar dos planos de papel a desafiar a realidade. Entre luzes e sombras, assistimos à ânsia de jovens críticos em aprender o máximo sobre educação e em deixar as suas marcas. Vimos também experiências bem sucedidas, que conseguiram aclimatar inovações de outros locais às suas necessidades e realidade. Com isso, giramos caleidoscópios cheios de cores, formas, paisagens e surpresas.

Por tudo isso, a prática da educação comparada e internacional é mesmo tão difícil por abarcar a relação entre eu e o outro, como se Abel e Caim, Eros e Tânatos coexistissem dentro de cada um de nós. Outras ciências da educação igualmente não são simples, porque a realidade é mesmo complexa e a sua simplificação, a rigor, só serve para fins didáticos.

Diante desse quadro de paradoxos, contradições, equívocos e incertezas a Unesco, há mais de 70 anos, situa a diversidade na centralidade dos desafios, organizando espaços para o diálogo entre culturas e civilizações e entre os que poderiam atenuar disparidades e reduzir discriminações. Assim, navega mundo afora com a esperança de que as mentes possam ser mudadas e direcionadas para concretizar, pelo menos, algumas utopias tão essenciais que não deveriam ser mais utopias, para manter vivas algumas expectativas para os outros, os párias das sociedades cada vez mais desiguais, as minorias, inclusive mulheres e meninas, os migrantes, enfim, os esquecidos dos direitos humanos, a "não gente", sediada em numerosos não lugares ou heterotopias. Apesar disso, conforme Bethencourt (2015, p. 512), "é preciso ainda percorrer um longo caminho para cumprir o sonho da dignidade humana e da real implementação dos direitos humanos", caminho que passa por uma escola acolhedora e humana, capaz de proporcionar a todos as aprendizagens necessárias à qualificação de uma verdadeira vida.

\section{Referências}

Amaral, M. P. (2015). Tendências, desafios e potenciais da educação internacional e comparada na atualidade. Revista Brasileira de Estudos Pedagógicos, 96(243), 259-281. 
Augé, M. (2010). Não lugares: introdução a uma antropologia da supermodernidade (9a ed.). Campinas: Papirus.

Bauman, Z. (2017). Estranhos à nossa porta. Rio: Zahar.

Beck, U. (2013). Sociedade de risco: rumo a uma outra modernidade. São Paulo: Ed. 34.

Bethencourt, F. (2015). Racismos: das cruzadas ao século XX. Lisboa: Temas e Debates, Círculo de Leitores.

Broadfoot, P. (2000). Comparative education for the 21st century: retrospect and prospect. Comparative Education, (36)3, Special Number (23), 357-371.

Camus, A. (2008). L'étranger. Paris: Gallimard.

Castells, M. (2011). Communication power. Nova lorque: Oxford.

Dubet, F. (2002). Le déclin de l'institution. Paris: Du Seuil.

Duby, G., Duby, A. (1973). Les procès de Jeanne d'Arc. Paris: Gallimard.

Elvin, L. (1972). Éducation. Pompei, G. F. et al. (Eds.). Dans l'esprit des hommes: Unesco 1946-1971 (pp. 15-43). Paris: Unesco.

Foucault, M. (2004). Des espaces autres. Empen, 54, 12-19.

Gomes, C.A. (2015). Educação comparada no Brasil: esboço de agenda. Revista Brasileira de Estudos Pedagógicos, 96(243), 243-258.

Homero (1997). Odisséia. São Paulo: Cultrix.

International Bureau of Education (2017). History. Recuperado de http://www.ibe.UNESCO.org/en/whowe-are/history.

Jesus, W.F. \& Gomes, C.A. (2016). Que países são estes? Educação Nova no Brasil e Portugal. Cunha, C., Jesus, W. F. \& Sousa, M. F (Eds.). Políticas de educação: cenários globais e locais (pp.67-90). Brasília: Liber Livro. Recuperado de https://socialeducation.files.wordpress.com/2015/01/politicade-educacao_completo.pdf.

Kant, I. ([1795] 2008). A paz perpétua: um projecto filosófico. Covilhã: Universidade da Beira Interior.

King, K. \& Martin, C. (2002). The vocational school fallacy revisited: education, aspiration and work in Ghana 1959-2000. International Journal of Education and Development, 22(1):5-26.

Nóvoa, A. (2017). État des lieux de l'éducation comparée: paradigmes, avancées et impactes. Recuperado de repositorio.ul.pt/bitstream/10451/4812/1/9782130514114_1_26.pdf

Nouss, A. (s/d.). Pensar o exílio e a migração hoje. Porto: afrontamento e instituto de literatura comparada Margarida Losa.

Ortega y Gasset, J. (2016). La deshumanización del arte. Barcelona: Austral Espasa.

Pedersen, S. (2007). Back to the league of nations. American History Review, 24(1), 31-45.

Pessoa, F. (2014). Mensagem. Rio: Calíope, 2014.

Pompei, G. F. (1972). Historique de l'Organisation. Pompei, G. F et al. (Eds.). Dans l'esprit des hommes: Unesco 1946-1971 (pp. 15-43). Paris: Unesco.

Simmel, G. (2012). El extranjero: sociología del extraño (pp. 21-26). Madri: Sequitur. 
Tácito. (1999). Germany. Warminster, UK: Aris \& Phillips.

Unesco. (2017). Education in emergency situations/achievements and challenge. Recuperado de http:// www.UNESCO.org/education/educprog/emergency/themes/situation.htm

Viana Filho, L. (2008). Anísio Teixeira: a polêmica da educação (3a ed.). São Paulo: UNESP; Salvador: EDUFBA.

\section{Candido Alberto Gomes}

Professor Catedrático da Universidade Portucalense Infante D. Henrique, Porto. Foi presidente da Sociedade Brasileira de Educação Comparada e presidente do Comitê de Pesquisa do Conselho Mundial das Sociedades de Educação Comparada.

E-mail: candidoacg@gmail.com ORCID: http://orcid.org/0000-0001-8498-3785

Correspondência

Candido Alberto Gomes

Universidade Portucalense Infante D. Henrique Rua Dr. António Bernardino de Almeida, 541

4200-072 Porto

Data de submissão: Outubro 2017

Data de avaliação: Março 2018

Data de publicação: Setembro 2018 